\title{
Treatment of cytomegalovirus retinitis with ganciclovir (9-[2-hydroxy-1-(hydroxymethyl) ethoxymethyl] guanine (BW B759U))
}

\author{
JUAN ORELLANA,' STEVEN A TEICH,' JACQUELINE S WINTERKORN,' \\ USHA MATHUR-WAGH, ${ }^{2}$ SANDRA HANDWERGER, ${ }^{2}$ HARAN SCHLAMM, \\ STEPHEN C MALAMUD, ${ }^{2}$ STANLEY R YANCOVITZ, ${ }^{2}$ \\ DONNA M CEDERBERG, ${ }^{3}$ AND DONNA S MILDVAN ${ }^{2}$
}

From the 'Department of Ophthalmology, Beth Israel Medical Center, and the Mount Sinai School of Medicine; ${ }^{2}$ Division of Infectious Diseases, Beth Israel Medical Center; and 'Burroughs Wellcome Company

SUMMARY Six patients (11 eyes) with virologically confirmed cytomegalovirus (CMV) retinitis involving the posterior pole of the eye were treated with a new drug, ganciclovir. Treatment with intravenous ganciclovir consistently halted progression of retinitis and produced improvement in measures of visual function. However, within three weeks after cessation of therapy renewed CMV activity and worsening of visual function were observed in most cases. Maintenance therapy with ganciclovir extended the period of remission from CMV retinitis.

The acquired immunodeficiency syndrome (AIDS) is an epidemic disorder characterised by immunological impairment that predisposes to the development of cancer and to life threatening infections with opportunistic organisms. The syndrome, first reported in homosexual men, and subsequently in intravenous drug abusers, recent Haitian immigrants, haemophiliacs, transfusion recipients, and infants of women in known risk groups for AIDS, has been well documented since 1981. ${ }^{1-3}$ Opportunistic infections including Pneumocystis carinii pneumonia, oral and oesophageal candidiasis, herpes simplex, herpes zoster, cytomegalovirus, systemic cryptococcus, atypical mycobacterial infections, and toxoplasmosis as well as Kaposi's sarcoma and nonHodgkin's lymphoma are frequently seen in these patients. ${ }^{1-7}$

Cytomegalovirus (CMV), a common and often severe opportunistic infection in these patients, may be present in the retina in the absence of clinically apparent cytomegalovirus infection elsewhere. The retinal manifestations of $\mathrm{CMV}$ are retinal necrosis with haemorrhages, exudates, retinal vasculitis, and

Correspondence to Juan Orellana, MD, Department of Ophthalmology, Beth Israel Medical Center. First Avenue at 16th Street, New York, New York 10003, USA. a slow but steady progression to complete retinal destruction. ${ }^{8-10}$

There is no efficacious treatment for either ocular or systemic cytomegalovirus infections. A new experimental intravenous drug, ganciclovir (BW B759U or (9-[2-hydroxy-1-(hydroxy-methyl) ethoxymethyl] guanine), an analogue of acyclovir, is being evaluated for the treatment of patients with CMV retinitis. This report describes an initial series of patients with AIDS and CMV retinitis who have received this new agent.

\section{Materials and methods}

The cases reported are the first six patients (11 eyes) with AIDS and CMV retinitis who consented to treatment at the Beth Israel Medical Center (BIMC) with the drug ganciclovir. The patients included five men and one woman, ranging in age from $29-55$, and all with history of homosexuality or intravenous drug abuse and a diagnosis of AIDS. All patients had positive urine cultures for $\mathrm{CMV}$ as well as increased serological titres for CMV. At the start of treatment their visual acuities ranged from 20/30 to no light perception (Table 1). All patients had disease involving the posterior pole, that is, involvement of either 525 
Table 1 Visual acuity after 21 days of therapy

\begin{tabular}{|c|c|c|}
\hline Patient & Before therapy & After therapy \\
\hline 1 & LP with projection OS & $20 / 3(0)$ OS \\
\hline \multirow[t]{2}{*}{2} & $20 / 30 \mathrm{OD}$ & NLPOD \\
\hline & $20 / 30 \mathrm{OS}$ & NLPOS \\
\hline \multirow[t]{2}{*}{3} & $20 / 50$ OS & $2(0 / 30)$ OS \\
\hline & $\mathrm{CF}$ at $2.4 \mathrm{~m}$ OD & $20 / 2(x)$ OD \\
\hline \multirow[t]{2}{*}{4} & NLPOD & NLP OD \\
\hline & $20 / 50 \mathrm{OS}$ & $20 / 50 \mathrm{OS}$ \\
\hline \multirow[t]{3}{*}{5} & $20 / 100) \mathrm{OD}$ & $2(1 / 70)$ OD \\
\hline & HMOS & HMOS \\
\hline & CF at $2 \cdot 4 \mathrm{~m}$ OD & $2(0 / 30 \mathrm{OD}$ \\
\hline 6 & $2(0 / 30) \mathrm{OS}$ & $2(0 / 30) O S$ \\
\hline
\end{tabular}

$\mathrm{NPL}=$ nolight perception $. \mathrm{LP}=$ light perception. $\mathrm{CF}=$ counting fingers. $\mathrm{HM}=$ hand motions

Complete blood counts including platelet counts, blood chemistries including liver function tests, electrolytes, blood urea nitrogen, and serum creatinine were obtained prior to initiating treatment and followed up at least every three days during therapy. In two patients on maintenance therapy these tests were performed once each week.

A complete ophthalmological examination was performed which included visual acuity testing, external and slit-lamp examination, intraocular pressure determination, and funduscopic evaluation. A baseline fluorescein angiogram, electroretinogram, and visual evoked reponse were performed on all patients. All patients received a baseline macular function test by the macula program of the Humphrey automated perimeter.

While in the hospital the patients had daily eye

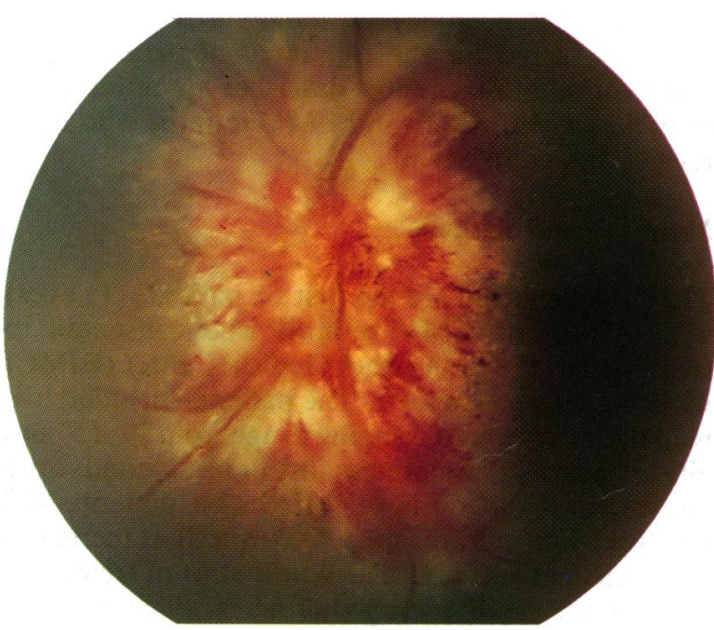

Fig. 1 Case 3. There is extensive involvement of the optic nerve head with obscuration of the disc. The visual acuity in this patient was $20 / 50$.

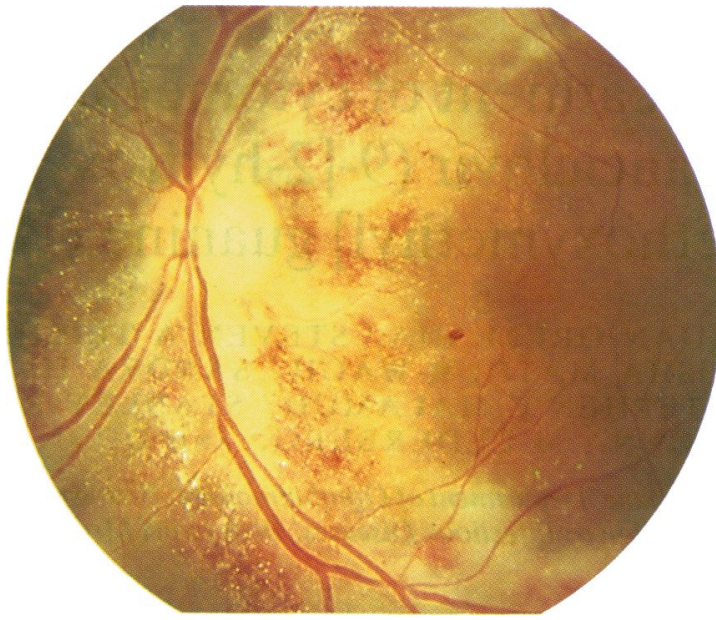

Fig. 2 After 21 days of therapy both the optic nerve and arcades are clearly visible. The acuity was stable at 20/30.

examinations, with fundus photography performed every third day. Macular function tests were repeated at least weekly, and fluorescein angiograms were repeated on a weekly basis.

All patients received ganciclovir $2.5 \mathrm{mg} / \mathrm{kg}$ intravenously every eight hours for a 21 -day course. Two patients received more than one course in hospital. Two of the patients received subsequent maintenance therapy after finishing the 21-day course. It consisted of $5 \mathrm{mg} / \mathrm{kg}$ intravenously once per day for

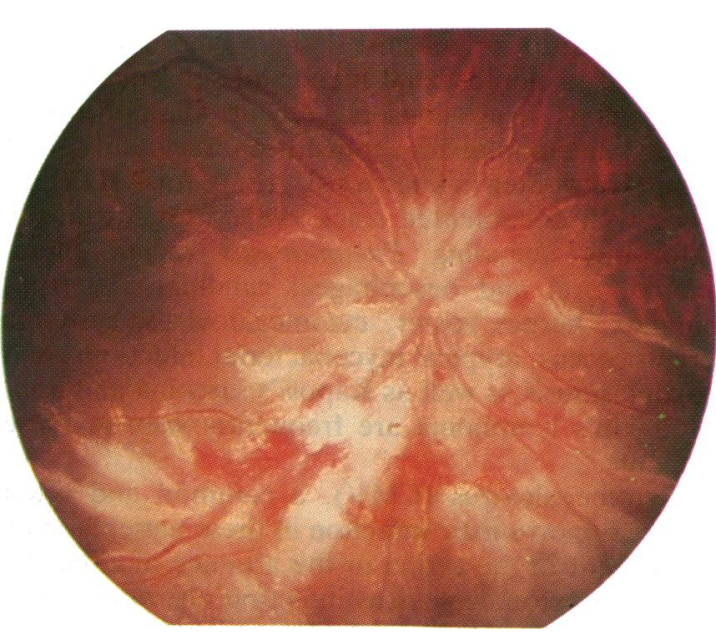

Fig. 3 Case 6. The patient's right eye demonstrates extensive involvement of the optic nerve head as well as the sheathing of the arteries and veins. There are some obliterated arteries inferior to the disc. There is extensive oedema throughout the posterior pole. The visual acuity was counting fingers at $2.4 \mathrm{~m}$. 


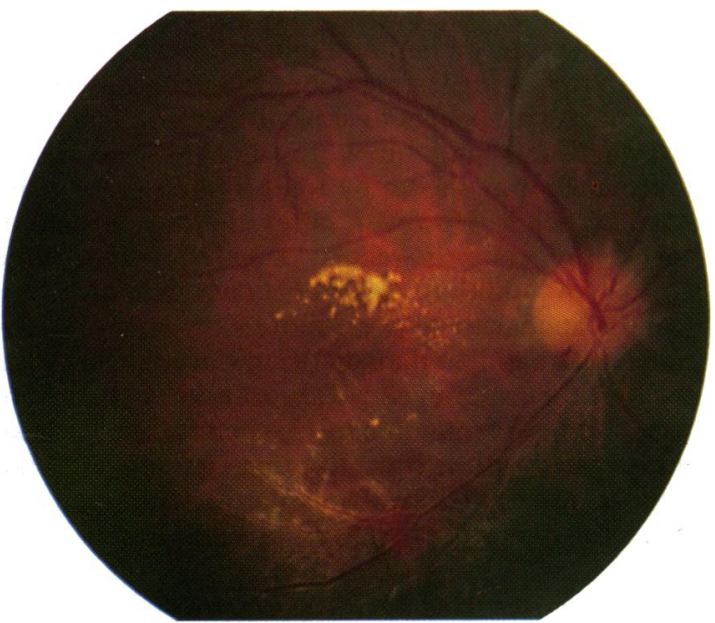

Fig. 4 After 10 days of therapy there is still some mild residual oedema of macula, and some borders of the optic nerve are now clearly visible. The acuity was 20/200.

five of seven days every week administered through a Broviac catheter placed into a subclavian vessel.

\section{Results}

We found that six of 11 eyes $(54.5 \%)$ improved their visual acuity by at least one line on the Snellen chart by the end of the 21-day course (Table 1, Figs. 1-5). Three eyes $(27 \cdot 2 \%)$ remained stable at pretherapy acuities and two eyes $(18 \cdot 1 \%)$ deteriorated. Patient 2

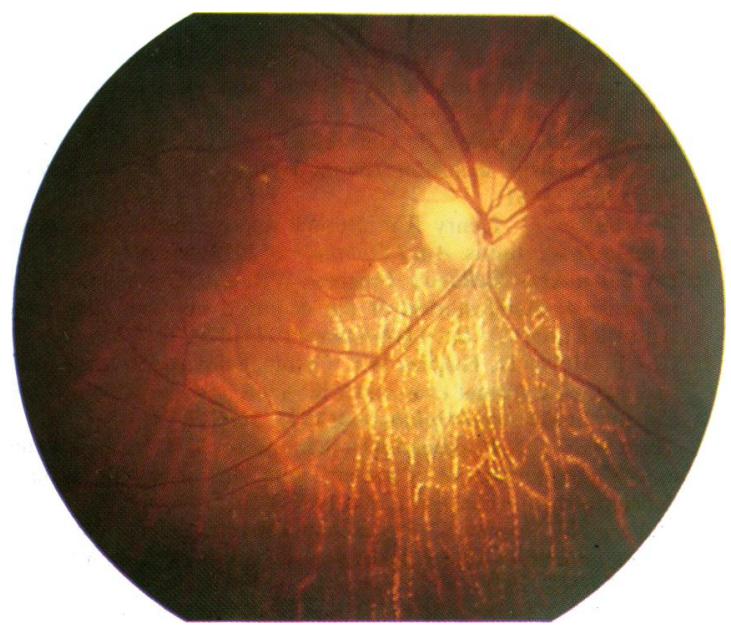

Fig. 5 While on maintenance therapy the fundus significantly cleared. The visual acuity progressed to 20130 in the right eye. The patient reported a great sense of wellbeing while on maintenance therapy. had both bilateral progressive scarring of the posterior pole and optic atrophy, resulting in a final visual acuity of no light perception. Thus ganciclovir improved or stabilised $81.7 \%$ of treated eyes. Two patients relapsed and required subsequent therapy more than once and lost an additional line of acuity on the Snellen chart; however, their final acuities remained better than their pretherapy acuities.

All patients had a drop in their white blood cell counts. In one case the dose of ganciclovir was decreased to $1 \mathrm{mg} / \mathrm{kg}$ intravenously every eight hours while the patient remained absolutely neutropenic (less than $1 \times 10^{4}$ white cells/l), and in another case the drug was terminated. The liver function values increased in five of the six patients; however, this did not interfere with the therapy regimen. Three of the six patients died after therapy, one from toxoplasmosis and two from disseminated CMV. One was lost to follow-up. These patients had not received maintenance therapy because they refused any further medications. One patient died from septicaemia while on maintenance therapy.

\section{Discussion}

Active CMV infection can be diagnosed by an increase in complement fixation antibodies, culture of the virus in serum, urine, saliva, or other body fluids, or biopsy confirmation of cells showing the classic histopathological picture. In the eye the virus has been isolated from tears ${ }^{11}$ or conjunctiva ${ }^{12}$ of patients with and without retinitis and does not correlate well with ocular symptoms. In patients with retinitis cultures of subretinal fluid and vitreous may be positive..$^{12-16}$ In patients with panuveitis aqueous taps have yielded live virus. ${ }^{1517}$ On occasion the diagnosis can be made by a vitreous tap and culture. ${ }^{911}$ CMV retinitis has been found in $15 \%$ to $46 \%$ of AIDS patients in most series from the United States. ${ }^{1222}$ Once observed in these patients, the retinitis tends to be slowly but inexorably progressive, often affecting both eyes and ultimately causing complete blindness.

Therapy for cytomegalovirus retinitis has been for the most part unsuccessful. Limited experiences with transfer factor ${ }^{23}$ and antiviral drugs such as adenine arabinoside,${ }^{24}$ floxacidine, and acyclovir have yielded only an occasional report of success. ${ }^{25-27}$ Clinically treatment with ganciclovir also did not appear to provide a permanent cure in the present series. Although this agent consistently halted the progression of the retinitis several days after initiation, and improved both the vision and the retina, these effects were maintained only during therapy and for a short time after drug therapy was withdrawn. ${ }^{28-33}$ Approximately three weeks after completion of a 
typical 21-day course, renewed CMV activity was observed in the retinas of cases $1,2,4$, and 5 .

Ganciclovir or BW B759U is an acyclic nucleoside analog of acyclovir. It is active against herpes simplex types I and II (HSV), varicella zoster virus (V2V), Epstein-Barr virus (EBV), and human cytomegalovirus (HCMV). In studies on human cytomegalovirus of strain AD169, BW B759U did not appear to affect virus early gene function. However, the synthesis of several late structural proteins was inhibited. ${ }^{3+}$ It appears that ganciclovir is incorporated by intranucleotide linkage into the DNA extracted from HSV infected cells. This suggests that it does not function as a chain terminator as does acyclovir. Ganciclovir strongly inhibits the synthesis of viral DNA in human cytomegalovirus infected cells as well as in herpes simplex virus infected cells. ${ }^{23}{ }^{35}$ In essence this new drug is phosphorylated and eventually functions as an alternative substrate, as a competitive inhibitor of the human cytomegalovirus induced DNA polymerase.

The main toxic effects of ganciclovir include reversible bone marrow depression and irreversible testicular atrophy. Assays done on the drug show that the toxicity falls between that of vidarabine and that of acyclovir. However, in patients with AIDS, HTLV-III/LAV virus also produces cytopenias and may synergistically act to decrease the white blood cell count, complicating evaluation of drug toxicity in these patients. Drug toxicity is believed to be minimal at $2.5 \mathrm{mg} / \mathrm{kg}$. At a dose of $5 \mathrm{mg} / \mathrm{kg}$ bone marrow suppression may occur. At a dosage of 7 $\mathrm{mg} / \mathrm{kg}$ per day in animal models testicular atrophy occurred..$^{36}$ At dosages of $20 \mathrm{mg} / \mathrm{kg}$ per day diarrhoea and emesis occurred in addition to cytostatic effects (bone marrow, thymus, lymphoid organs) and testicular atrophy. At large doses of $60 \mathrm{mg} / \mathrm{kg}$ per day animals experienced diarrhoea and emesis, cytostatic effects, testicular atrophy, maturation arrest of gastrointestinal cells, and death.

In the early patients reported here, no side effects were noted other than a decrease in the white blood cell count. In most patients it decreased slightly, and in two the treatment was reduced or stopped until the white blood cell count returned to normal. One case (3) experienced a transient decrease in the white blood cell count several days after finishing a first 10day course of therapy. It could not be determined, however, whether this represented a delayed effect of the ganciclovir therapy or a consequence of other concurrent medications, the direct effect of the CMV itself, or the underlying immune deficiency. More interesting was that many of these patients stated they had an improved feeling of general wellbeing while on the drug. Those patients who had headaches noted improvement while on therapy. One can theorise that the medication may be able to enter the central nervous system and inhibit the virus despite animal studies suggesting poor CNS penetration.

Ganciclovir appears to slow or halt progression of CMV retinitis and allow for healing and visual improvement as shown by fundus photographs and macular fields. However, after therapy is discontinued the retinitis recurs, usually within three weeks. In addition recurrent episodes of CMV retinitis appear to respond more slowly and incompletely to treatment than do the initial episodes. As a result of the experience we report here, patients are being put on a maintenance schedule of $5 \mathrm{mg} / \mathrm{kg}$ intravenously in one dose, five times a week, after the initial course of therapy is completed. It is hoped that such a regimen will prevent recurrent retinitis.

The authors express their thanks to Burroughs Wellcome Company for providing them with the drug BW B759U.

\section{References}

1 Centers for Disease Control. Update on acquired immune deficiency syndrome (AIDS)-United States. Morbid Mortal Weekly Rep 1982; 31: 507

2 Centers for Disease Control. Pneumocystis pneumonia-Los Angeles. Morbid Mortal Weekly Rep 1981; 30: 250-2.

3 Centers for Disease Control. Kaposi`s sarcoma and pncumocystic pneumonia among homosexual men-New York City and California. Morbid Mortal Weekly Rep 1981; 30: 305-8.

4 Hymes KB, Cheung T, Greene JB, et al. Kaposi's sarcoma in homosexual men. A report of eight cases. Lancet 1981; ii: 598.

5 Gottlicb MS, Schroff R, Schanker HM, et al. Pneumocystis carinii pneumonia and mucosal candidiasis in previously healthy homosexual men. Evidence of a new acquired cellular immunodeficiency. N Engl J Med 1981; 305: 1425-31.

6 Siegal FP. Lopez C. Hammer GS, et al. Severe acquired immunodeficiency in malc homosexuals, manifested by chronic, perianal ulcerative herpes simplex lesions. N Engl J Med 1981 305: $1439-44$.

7 Mildvan D, Mathur U, Enlow RW, et al. Opportunistic infections and immune deficiency in homosexual men. Ann Intern Med 1982; 96: 700-4

8 Wyhinny CJ, Apple DJ, Guastella FR, Vygantas CM. Adult cytomegalovirus inclusion retinal-uveitis. Am J Ophthalmol 1973; 76: 773-81

9 Augsburger JJ, Henry RY. Retinal aneurysms in adult cytomegalovirus retinitis. Am J Ophthalmol 1978; 86: 794-7.

10 Friedman AH, Orellana J, Freeman WR, et al. Cytomegalovirus retinitis. A manifestation of the acquired immune deficiency syndrome (AIDS). Br J Ophthalmol 1983; 67: 372-80.

11 Cox F, Meyer D, Hughes WT. Cytomegalovirus in tears from patients with normal eyes and with acute cytomegalovirus and chorioretinitis. Am J Ophthalmol 1975; 80: 817-24.

12 Teich SA, Tay S, Friedman AH, Schmitterer MD. Viral particles in the conjunctiva of a patient with the acquired immune deficiency syndrome. Am J Med 1987; 82: 151-2.

13 Aaberg TM, Cessarz TJ, Rytell MW. Correlation of virology and clinical course of cytomegalovirus retinitis. Am J Ophthalmol 1972; 74: 407-15.

14 Burns RP. Cytomegalic inclusion disease uveitis. Report of a case with isolation from aqueous humour of the virus in tissue culture. Arch Ophthalmol 1959; 61: 376-87.

15 Nicholson DH. Cytomegalovirus infection of the retina. Int Ophthalmol Clin 1975; 15: 151-62. 
16 Broughton WL, Cupples HP, Parver LM. Bilateral retinal detachment following cytomegalovirus retinitis. Arch Ophthalmol 1978; 96: 618-9.

17 Berger BB, Weinberg RS, Tessler HH, Wyhinny GJ, Vygantas $\mathrm{CM}$. Bilateral cytomegalovirus panuveitis after high dose corticosteroid therapy. Am J Ophthalmol 1979; 88: 1020-5.

18 Holland GN, Pepose JS, Pettit TH, Gottlieb MS, Yee RD, Foos RY. Acquired immune deficiency syndrome: ocular manifestations. Ophthalmology 1983; 90: 859-72.

19 Palestine AG, Rodriguez MM, Macher AM, et al. Ophthalmic involvement in acquired immunodeficiency syndrome. Ophthalmology 1984; 91: 1092-9.

20 Freeman WR, Lerner CW, Mines JA, et al. A prospective study of the ophthalmologic findings in the acquired immune deficiency syndrome. Am J Ophthalmol 1984; 97: 133-42.

21 Newsome DA, Green WR, Miller ED, et al. Microvascular aspects of acquired immune deficiency syndrome retinopathy. Am J Ophthalmol 1984; 98: 590-601

22 Khadem M, Kalich SB, Goldsmith J, et al. Ophthalmologic findings in acquired immune deficiency syndrome (AIDS). Arch Ophthalmol 1984; 102: 201-6.

23 Keith CG, Lanauze J. Cytomegalovirus retinitis. Med J Aust 1980; i: $24-6$.

24 Pollard RB, Egbert PR, Gallagher JG, Merigan TC. Cytomegalovirus retinitis in immunosuppressed hosts. I. Natura history and effects of treatment with adenine arabinoside. Ann Intern Med 1980; 93: 655-64.

25 Drew WL, Mintz L, Miner RC, Sands M, Ketterer B. Prevalence of cytomegalovirus in homosexual men. J Infect Dis 1981; 143: 188-92.

26 Chumbley LC, Robertson DM. Smith TF, et al. Adult cytomegalovirus inclusion retino-uveitis. Am J Ophthalmol 1975; 80: 807-16.

27 Cogan DG. Immunosuppression in eye disease. Am J Ophthalmol 1977; 83: 777-88.

28 Palestine AG, Stevens G, Lane HC, et al. Treatment of cytomegalovirus retinitis with dihydroxy propoxymethyl guanine. Am J Ophthalmol 1986; 101: 95-101.

29 Masur H, Lane HC, Palestine A, et al. Effect of 9-(1,3 dihydroxy-2-propoxymethyl) guanine on serious cytomegalovirus disease in eight immunosuppressed homosexual men. Ann Intern Med 1986; 104: 41-4.

30 Collaborative DHPG Treatment Study Group. Treatment of serious cytomegalovirus infections with 9-(1,3-dihydroxy-2propoxymethyl) guanine in patients with AIDS and other immunodeficiencies. N Engl J Med 1986; 314: 801-5.

31 Rosecan LR, Stahl-Bayliss CM, Kalman CM, Laski OL. Antiviral therapy for cytomegalovirus retinitis in AIDS with dihydroxy propoxymethyl guanine. Am J Ophthalmol 1986; 101: 405-18.

32 Felsenstein D, D'Amico DJ, Hirsch MS, et al. Treatment of cytomegalovirus retinitis with 9-[2-hydroxy-1-(hydroxymethyl) ethoxymethyl] guanine. Ann Intern Med 1985; 103: 377-80.

33 Bach MC, Bagwell SP, Knapp NP, et al. 9-(1,3-dihydroxy-2propoxymethyl) guanine for cytomegalovirus infections in patients with the acquired immunodeficiency syndrome. Ann Intern Med 1985; 103: 381-2.

34 Mar EC, Cheng YC, Huang ES. Effect of 9-(1,3-dihydroxy2-propoxymethyl) guanine on human cytomegalovirus replication in vitro. Antimicrob Agents Chemother 1983; 24: 51821.

35 Tocci MJ, Livelli TJ, Perry HC, Crumpacker CS, Field AK. The effects of the nucleoside analog 2'-nor-2'deoxyguanosine on human cytomegalovirus replication. Antimicrob Agents Chemother 1984; 25: 247-52.

36 Burroughs Wellcome Company Document TTEP/84/0016.

Accepted for publication 23 April 1987 